Article

\title{
Effect of Postharvest LED Application on Phenolic and Antioxidant Components of Blueberry Leaves
}

\author{
Winny Routray *(1), Valerie Orsat and Mark Lefsrud \\ Bioresource Engineering Department, Macdonald Campus, McGill University, Ste-Anne-de-Bellevue, \\ QC H9X 3V9, Canada; valerie.orsat@mcgill.ca (V.O.); mark.lefsrud@mcgill.ca (M.L.) \\ * Correspondence: routrayw@yahoo.com
}

Received: 18 September 2018; Accepted: 15 November 2018; Published: 20 November 2018

\begin{abstract}
Light from red $(661 \mathrm{~nm})$ and blue (417 nm) LEDs were applied for 12, 24, and $48 \mathrm{~h}$ on freshly harvested blueberry leaves of different cultivars mixed together. The extracts obtained through microwave extraction of these leaves were analysed in terms of total phenolic content, total monomeric anthocyanin content, and antioxidant activity as measured by \% scavenging 2,2-diphenyl-1-picrylhydrazyl (DPPH) scavenging activity and ferric reducing antioxidant potential (FRAP). It was observed that although the content of total phenolic content was high in the untreated leaves, there was an increase in the phenolic content and monomeric anthocyanin content of the leaves treated with blue light. DPPH inhibition activity and FRAP for all the samples were high; however, there was an increase in the FRAP of samples treated with light for different durations, which varied with type of light and the time of application of the LED light.
\end{abstract}

Keywords: blueberry; leaves; LED; antioxidant; phenolics; anthocyanins

\section{Introduction}

Blueberry leaves have been considered as an important source of phenolic compounds [1,2], which can be processed using several postharvest applications, including extraction, separation, purification, and encapsulation leading to viable product development and commercialisation of different blueberry phenolic compounds (chlorogenic acid [3], catechin, epicatechin, caffeic acid, and different anthocyanins [4]) or for application in nutraceutical purposes and as food additives. Blueberry leaves have been reported to have antioxidant activities comparable or higher than the fruits $[1,2,5]$ and several other health beneficial effects including antidiabetic [6] and antibacterial effects [7].

Postharvest processing methods affect the concentration of these compounds in the plant sources. In the past few decades, research on postharvest application of different abiotic sources of stress has been increasingly conducted. It was indicated that sources of stress such as wounding, phytohormones, temperature, ultraviolet light, altered gas composition, heat shock, and water stress, among others can affect and trigger the secondary metabolism of fresh biological material leading to increased synthesis of desirable phytochemicals [8]. Abiotic stress application has been reported to affect the pathways for biosynthesis of some groups of secondary metabolites including terpenes, phenolics, and nitrogen containing compounds (polyamines and glycine betaine $[9,10]$ ). UV-B and UV-C has been observed to have a significant positive effect on phenolic compounds concentration in various fruits including blueberries, apples, and elderberries [11,12].

Light emitting diodes have been applied as a source of light in many cases for the cultivation of various crops and application of LEDs has been reported to have desirable positive effects on the phytochemical composition of the end bioproducts $[13,14]$. LEDs have been proposed to be one of the most effective sources of light for application in the study of plant responses to different radiation 
spectra, because of the narrow band spectra of a number of wavelengths [15]. LEDs have been applied as a combination of various wavelengths, such as red and blue together, which have been observed to give better results than application of one type of LEDs alone, as observed in the case of red curled lettuces [13]. Similarly, application of LEDs might be more helpful in tracking the specific postharvest effects of various particular wavelengths of light on the biomaterials and in studying the mechanisms involved.

This manuscript summarizes the preliminary studies conducted by postharvest application of red and blue LED on the freshly harvested blueberry leaves, to observe the effect of the LED application, as a function of different time periods, on the quantities of total phenolics, total monomeric anthocyanins and the antioxidant activity measured in terms of percentage of scavenging of DPPH and in terms of FRAP. For analytical measurements, the blueberry leaf extracts were obtained using a microwave-assisted extraction method which has been discussed in our previous publications $[3,16]$.

\section{Materials and Methods}

\subsection{Preparation of Blueberry Leaf Sample}

Leaves of different cultivars of highbush blueberry (Vaccinium corymbosum L.) were harvested during the fall of 2013 from Quinn Farm (Notre-Dame-de-l'Ile-Perrot, Quebec, QC, Canada). Green leaves were collected from plants growing in a small plot, on the same day. The leaves were uniformly mixed, before being processed and employed for the detailed experimentation and analyses. Approximately $10 \mathrm{~g}$ of uniformly-mixed leaves was freeze-dried (Freezone ${ }^{\circledR} 2.51$ Freeze Dry System, Labconco Corporation, Kansas City, MO, USA), to determine their initial moisture content which was estimated to be $61.55 \%$ (wet basis).

Samples prepared with another portion of fresh blueberry leaves were subjected to postharvest LED applications and colour indices of the leaves were measured at regular intervals. After the measurement of colour indices, the leaves samples were freeze-dried. The dried leaves were ground and stored at $-18{ }^{\circ} \mathrm{C}$ for further analyses.

\subsection{Application of LED and Measurement of Colour Indices}

LED application was conducted at room temperature, which was maintained between 20 to $25{ }^{\circ} \mathrm{C}$. The leaves were spread uniformly as a single layer, over the white surface on a plastic tray, for uniform application of LED. The colour indices $(L, a$, and $b)$ of individual leaves were measured using a Colorimeter (Konica Minolta, Japan). The LED arrays (Orbitec, Madison, WI, USA) were fixed at a height of $39.4 \mathrm{~cm}$ (15.5 inches) from the centre of the tray surface. The time periods of application of LEDs, including red light with wavelength $661 \mathrm{~nm}$ and blue light with wavelength $417 \mathrm{~nm}$ were fixed at 12, 24, and $48 \mathrm{~h}$. The applied photosynthetic photon flux densities were measured using a quantum meter (Model QMSS-ELEC, Serial number 1496, Apogee Instruments Inc., Logan, UT, USA) as $6 \mu \mathrm{mol} \mathrm{m}{ }^{-2} \mathrm{~s}^{-1}$ and $24 \mu \mathrm{mol} \mathrm{m}{ }^{-2} \mathrm{~s}^{-1}$ for blue and red LEDs respectively. After the scheduled time of application of LEDs, the colour indices $\left(L^{*}, a^{*}\right.$, and $\left.b^{*}\right)$ of the leaves were measured again. The total colour change $(\delta E)$ of leaves was calculated according to Equation (1):

$$
\delta E=\left[\left(L-L^{*}\right)^{2}+\left(a-a^{*}\right)^{2}+\left(b-b^{*}\right)^{2}\right]^{0.5}
$$

\subsection{Extraction and Analysis of Different Compounds and Antioxidant Activity}

All chemicals used during the study were of analytical grade (Greenfield Ethanol Inc., Brampton, ON, Canada; Sigma-Aldrich, St-Louis, MO, USA; Fisher Scientific, Nepean, ON, Canada). Blueberry leaves extract were obtained using microwave extraction for $24 \mathrm{~min}$ at $20 \%$ power level, with solvent combination of $77.6 \mathrm{~mL} \mathrm{30 \%} \mathrm{ethanol} \mathrm{solution} \mathrm{and} 2.4 \mathrm{~mL}$ of $1.5 \mathrm{M}$ citric acid solution, in a microwave digester ((Star system 2, CEM Mathews, Stallings, NC, USA) with a nominal power level of $800 \mathrm{~W}$ at $2450 \mathrm{MHz}$ ). Total phenolic content, total monomeric anthocyanin content, \% scavenging 
2,2-diphenyl-1-picrylhydrazyl (DPPH) and ferric reducing antioxidant potential (FRAP) analysed using methods described in our previous studies conducted on blueberry leaves [3,16]. Extraction and corresponding chemical analyses were conducted in triplicate.

\subsection{Statistical Design and Analyses}

Statistical analyses were conducted using JMP 10 (SAS Institute Inc., Cary, NC, USA). Statistical design 1 consisted of combinations of categorical factor "type of light" (red and blue) and continuous factor "time of application" $(12,24$, and $48 \mathrm{~h}$ ), with a total of 18 combinations (six combinations with three replicates of each combination). The second experiment was designed with "type of light" and "time of application", both considered as categorical factors with a total of 18 combinations, for which comparison of Least Squares (LS) means were conducted with Student's $t$-test and Tukey's HSD (Honest significant difference) analysis for all the responses. For all statistical designs, all levels of a factor or combinations of levels of factors were conducted in triplicate.

\section{Results and Discussion}

\subsection{Overall Effect of the Application of LED on Different Phytochemicals Concentration}

Several reports have mentioned the increase in the total content of phenolic compounds and anthocyanins in plant material due to the abiotic stress. LED light has generally been applied during cultivation of different plants leading to activation of different secondary metabolic pathways and interconversion of compounds of interest. Table 1 summarizes the content of total polyphenols, total monomeric anthocyanins, antioxidant capacity (DPPH), and reducing power (FRAP) of blueberry leaves extracts prepared after a respective time of application of different wavelengths of LEDs. The application of blue light for $12 \mathrm{~h}$ increased the concentration of total phenolics as compared to extract obtained from untreated leaves and the application of up to $24 \mathrm{~h}$ increased, maintained, or decreased the phenolic concentration (which has led to high standard deviation), however the application for $48 \mathrm{~h}$ led to deterioration of the compounds in all observed cases. Nonetheless, the application of red light led to a decrease in phenolic content as compared to untreated leaves, which decreased further with an increase in time of light application.

Table 1. Summary of the total phenolics, total monomeric anthocyanins and antioxidant activity of blueberry leaf extracts after light treatment.

\begin{tabular}{|c|c|c|c|c|c|c|}
\hline Light & Level & Time (h) & $\begin{array}{l}\text { Total Phenolics } \\
\text { (mg GAE/g Dry } \\
\text { Matter) }\end{array}$ & $\begin{array}{c}\text { Total Monomeric } \\
\text { Anthocyanins (mg M } \\
\text { 3-G Equiv./g Dry Matter) }\end{array}$ & $\begin{array}{c}\text { \% Scavenging } \\
\text { (DPPH) }\end{array}$ & $\begin{array}{c}\text { FRAP (mg AA } \\
\text { Equiv./g Dry } \\
\text { Matter) }\end{array}$ \\
\hline \multicolumn{3}{|c|}{ Untreated Batch } & $160.962 \pm 1.446^{\mathrm{a}}$ & $1.108 \pm 0.271^{a, b}$ & $88.476 \pm 0.755^{\mathrm{a}, \mathrm{b}}$ & $231.600 \pm 18.474^{b}$ \\
\hline Blue & 2 & 12 & $161.709 \pm 8.286^{\mathrm{a}}$ & $1.076 \pm 0.259^{a, b}$ & $87.797 \pm 0.367^{b, c}$ & $245.563 \pm 18.474^{\mathrm{a}, \mathrm{b}}$ \\
\hline Blue & 2 & 24 & $159.285 \pm 7.637^{\mathrm{a}, \mathrm{b}}$ & $1.501 \pm 0.989^{\mathrm{a}}$ & $87.924 \pm 0.334^{\mathrm{a}, \mathrm{b}, \mathrm{c}}$ & $247.970 \pm 5.325^{\mathrm{a}, \mathrm{b}}$ \\
\hline Blue & 2 & 48 & $147.871 \pm 7.269^{b, c}$ & $0.701 \pm 0.054^{\mathrm{b}}$ & $88.375 \pm 0.290^{a, b}$ & $248.433 \pm 13.520^{\mathrm{a}, \mathrm{b}}$ \\
\hline Red & 2 & 12 & $154.982 \pm 3.374^{\mathrm{a}, \mathrm{b}}$ & $0.732 \pm 0.142^{b}$ & $88.693 \pm 0.295^{a}$ & $261.619 \pm 19.194^{\mathrm{a}}$ \\
\hline Red & 2 & 24 & $150.861 \pm 2.003^{a, b, c}$ & $0.761 \pm 0.115^{b}$ & $88.275 \pm 0.492^{\mathrm{a}, \mathrm{b}}$ & $226.322 \pm 8.662^{b}$ \\
\hline Red & 2 & 48 & $138.901 \pm 11.521^{\mathrm{C}}$ & $0.793 \pm 0.216^{\mathrm{a}, \mathrm{b}}$ & $87.288 \pm 0.623^{c}$ & $228.989 \pm 4.860^{b}$ \\
\hline
\end{tabular}

Note: Levels not connected by same letter $(\mathrm{a}, \mathrm{b}, \mathrm{c})$ are significantly different. The amounts reported in the Table are average with standard deviation. GAE = Gallic acid equivalent; AA Equiv. = Ascorbic acid Equivalent.

The content of monomeric anthocyanins increased with time up to $24 \mathrm{~h}$ during the application of blue light, after which it decreased. In case of application of red light, the quantity increased with an increase of time but was lower than the untreated sample (Table 1), which might be a combined effect of accumulation due to the activation of secondary metabolic pathways and the degradation effect of the light leading to postharvest anthocyanin losses. Light mediated anthocyanin degradation was observed in case of pomerac (Syzygium malaccense), where anthocyanin absorbance levels were much lower in the samples stored under light as compared to samples stored in dark [17]. The total phenolics and total monomeric anthocyanins varied among the replicates, which can be explained because of the 
fact that the samples collected were a mix of different cultivars of blueberry leaves. Hence, due to the inherent variation of the nature of the biological material, the reaction to external stress factors varied.

There are no reported examples of postharvest application of blue or red LEDs, however, in a study by Britz et al., the postharvest application of deep UV radiation using LEDs were observed to increase the shelf-life of strawberries [18]. Some wavelengths of light have been reported to have a superior impact on the synthesis and accumulation of total phenolics than other wavelengths, as observed in the greenhouse cultivation of baby lettuce [19]. This can also explain the comparatively higher concentration of phenolics and anthocyanins found in the leaves exposed to blue light than red light in the current case. For red curled lettuce grown under different wavelengths of light, anthocyanin content was observed to be the highest in cases with the combined application of blue and red lights, however anthocyanin synthesis was observed to be inhibited by the monochromatic red light [13].

\subsection{Overall Effect of the Application of LED on Antioxidant Activity}

Stress conditions, such as application of far-infrared radiations, wounding, or different postharvest storage conditions, have been observed to increase the antioxidant activity in different biomaterials including different fruits and vegetables [8]. In the current study, the percentage scavenging capacity of DPPH of the light treated samples was similar to the untreated sample (Table 1). Environmental factors significantly contribute to the composition and related properties of the plant materials, including antioxidant activity [20-23]. In the current study, the leaves were harvested during the fall season, which might be the reason of the similarity between untreated and light treated samples. The accumulation or the synthesis of phytochemicals in the different parts of the plant reaches a point of saturation during the growth of a plant. In our earlier study [24], it was observed that blueberry leaves collected in October had higher total phenolics content, anthocyanin content, and percentage scavenging capacity of DPPH and FRAP compared to the leaves harvested in May, July, and September. Similar observations were reported in case of Rabbiteye Blueberry (Vaccinium ashei) leaves [25]. High anthocyanin content has been associated with the autumn colours and has physiological significance in case of senescing leaves [26,27]. Fall season is the last harvest season of blueberries, hence the end of the period of cultivation in the cycle of a year, which is the time when the leaves reach the point of saturation of phytochemicals and antioxidant activity [24-27], hence the DPPH scavenging activity of the untreated blueberry leaves were similar to the treated blueberry leaves. However, FRAP of the leaves treated with blue light was higher as compared to untreated samples which increased slightly with time. The extract prepared with leaves treated with red light for $12 \mathrm{~h}$ had higher FRAP than both untreated and the other treated samples with both red and blue light. However, it was observed that FRAP of samples treated with blue light was maintained at a higher level as compared to samples treated with red light for 24 and $48 \mathrm{~h}$. The rate of decline of ferric reducing antioxidant potential was higher in samples treated with red light than observed in case of samples treated with blue light. In one of the previous reported studies, samples treated with red light had higher Trolox equivalent antioxidant capacity as compared to blue light application of LED on pea seedlings [28]. Overall, the antioxidant activities of all the samples were high. Results were similar to the highest levels of antioxidant activity obtained for the leaves harvested in the early and late fall season in the previous study of variation of antioxidant activity of the blueberry leaves extract with harvest season [24]. Results were also similar to the higher levels of antioxidant activities obtained in case of study of effect of drying parameters on the antioxidant activity of the blueberry leaves extracts [16].

Overall, although the concentration of the analysed phytochemicals and antioxidant activities were not significantly different, however, based on the results obtained, the possible increase and/or retention of the phytochemicals and their corresponding activity in the leaves can be proposed, which should be further analysed through more elaborated and structured experimental designs with different cultivars. The positive effects of LEDs have been reported in earlier studies with 
other biomaterials. Based on current preliminary observations, positive effects of postharvest LEDs application on leaves can be expected.

\subsection{Statistical Analysis}

The analysis of variance (ANOVA) analyses results are summarised in Table 2. The relative variation among the highest and lowest responses was low, the $\mathrm{R}^{2}$ value was low and the model was not significant in the case of total monomeric anthocyanin obtained and FRAP. The different factors of light and time of application were only significant in case of total phenolic content, where it can be interpreted that with an increase in time of application of light, the total phenolic content decreased (Table 1). The interaction between type of light and time of application was only significant in case of DPPH scavenging activity. In the case of both wavelengths, the monomeric anthocyanin content decreased with increased period of the application of light, which can be attributed to the deterioration of anthocyanin with longer period of light application, as has been observed in the previous cases of degradation of anthocyanins with exposure to light in case of pomerac (Syzygium malaccense) as compared to samples stored in dark [17]. Shorter time periods of application of blue light resulted in higher concentrations of monomeric anthocyanins. Hence, it can be deduced that the application of blue light for a shorter period of time might be a better option for obtaining high values of anthocyanins.

Table 2. Summary of the results obtained from ANOVA analysis of the responses obtained and the corresponding parameter estimates of the different factors in first statistical design with categorical factor light and continuous factor time (h) of application.

\begin{tabular}{|c|c|c|c|c|c|c|c|c|}
\hline \multirow[t]{3}{*}{ Terms } & \multicolumn{2}{|c|}{$\begin{array}{l}\text { Total Phenolic Content (mg } \\
\text { GAE/g Dry Matter) }\end{array}$} & \multicolumn{2}{|c|}{$\begin{array}{l}\text { Total Monomeric Anthocyanins } \\
\text { (mg M 3-G Equiv/g Dry Matter) }\end{array}$} & \multicolumn{2}{|c|}{$\begin{array}{l}\text { \% Scavenging } \\
\text { (DPPH) }\end{array}$} & \multicolumn{2}{|c|}{$\begin{array}{l}\text { FRAP (mg AAE/g } \\
\text { Dry Matter) }\end{array}$} \\
\hline & \multicolumn{2}{|c|}{$\begin{aligned} R^{2} & =0.60539 \\
\mathrm{RMSE} & =6.908147\end{aligned}$} & \multicolumn{2}{|c|}{$R^{2}=0.235918, \mathrm{RMSE}=0.450349$} & \multicolumn{2}{|c|}{$\begin{array}{c}R^{2}=0.635456 \\
\mathrm{RMSE}=0.388165\end{array}$} & \multicolumn{2}{|c|}{$\begin{array}{c}R^{2}=0.318337 \\
\mathrm{RMSE}=15.10236\end{array}$} \\
\hline & $\begin{array}{l}\text { Parameter } \\
\text { estimate }\end{array}$ & Prob $>$ F & $\begin{array}{l}\text { Parameter } \\
\text { estimate }\end{array}$ & Prob $>$ F & $\begin{array}{l}\text { Parameter } \\
\text { estimate }\end{array}$ & Prob $>$ F & $\begin{array}{l}\text { Parameter } \\
\text { estimate }\end{array}$ & Prob $>$ F \\
\hline Intercept & 151.41652 & $<0.0001 *$ & 0.9152788 & $<0.0001^{*}$ & 88.035981 & $<0.0001$ * & 242.45946 & $<0.0001^{*}$ \\
\hline Light [Blue] & 4.0768398 & $0.0264 *$ & 0.150036 & 0.1830 & 0.0290972 & 0.7572 & 5.0049603 & 0.1852 \\
\hline Time (h) & -7.66342 & 0.0016 * & -0.108726 & 0.4087 & -0.205911 & 0.0823 & -6.209325 & 0.1690 \\
\hline $\begin{array}{l}\text { Light [Blue] } \\
\text { Time }(\mathrm{h})\end{array}$ & 0.5097403 & 0.7984 & -0.138083 & 0.2977 & 0.5020415 & 0.0004 * & 7.4890873 & 0.1021 \\
\hline Model & & $0.0038 *$ & & 0.2731 & & $0.0022 *$ & & 0.1360 \\
\hline Lack of fit & & 0.8953 & & 0.2515 & & 0.9628 & & 0.0678 \\
\hline
\end{tabular}

Note: ${ }^{*}$ signify that the term is significantly affecting the response. AAE: Ascorbic acid equivalent

According to the student's t-test and Tukey's HSD analyses of comparison of LS means (Table 3), no significant difference of the response was observed between the types of lights other than in the case of total phenolics. Only the application of light for $48 \mathrm{~h}$ was observed to give significantly less total phenolics than during the application of light for 12 and $24 \mathrm{~h}$. In the case of all other measured responses, there was no significant effect of different time periods of application of light. Among the interaction effects of time and wavelength, there is overlap between the connecting letters indicating similarities between the different responses. There was no significant interaction of the combinations of the factors levels on the total monomeric anthocyanins and FRAP (Table 3). However, for the total phenolic extraction, blue light applied for $12 \mathrm{~h}$ had a significantly different effect than red light applied for $48 \mathrm{~h}$, which leads to a much higher yield of total phenolics in the blueberry leaf extracts. Overall, though the DPPH scavenging activity was high for all samples, there was significant difference between the DPPH activity of the extracts obtained with red light applied for $12 \mathrm{~h}$ and $48 \mathrm{~h}$, where $12 \mathrm{~h}$ application of red light led to higher DPPH scavenging activity than for $48 \mathrm{~h}$. 
Table 3. Summary of Student's $t$-test and Tukey's HSD analysis of comparison of LS means for experimental design with categorical factors light and time interval (2nd statistical design) to analyse the effect on different extracted component.

\begin{tabular}{|c|c|c|c|c|c|c|c|c|}
\hline \multirow[t]{2}{*}{ Level } & \multicolumn{2}{|c|}{ Total Phenolic Content } & \multicolumn{2}{|c|}{$\begin{array}{c}\text { Total Monomeric } \\
\text { Anthocyanin Content }\end{array}$} & \multicolumn{2}{|c|}{ \% Scavenging (DPPH) } & \multicolumn{2}{|c|}{$\begin{array}{c}\text { FRAP (mg AAE/g Dry } \\
\text { Matter) }\end{array}$} \\
\hline & $\begin{array}{l}\text { Connecting } \\
\text { Letters }\end{array}$ & $\begin{array}{l}\text { Least Sq. } \\
\text { Mean }\end{array}$ & $\begin{array}{l}\text { Connecting } \\
\text { Letters }\end{array}$ & $\begin{array}{l}\text { Least Sq. } \\
\text { Mean }\end{array}$ & $\begin{array}{l}\text { Connecting } \\
\text { Letters }\end{array}$ & $\begin{array}{l}\text { Least Sq. } \\
\text { Mean }\end{array}$ & $\begin{array}{l}\text { Connecting } \\
\text { Letters }\end{array}$ & $\begin{array}{l}\text { Least Sq. } \\
\text { Mean }\end{array}$ \\
\hline \multicolumn{9}{|c|}{ Light } \\
\hline Blue & A & 156.28822 & A & 1.0927381 & A & 88.032175 & A & 247.32222 \\
\hline Red & B & 148.24781 & A & 0.7619810 & A & 88.085545 & A & 238.97654 \\
\hline \multicolumn{9}{|c|}{ Time (h) } \\
\hline 12 & A & 158.34545 & A & 0.9042000 & A & 88.245357 & A & 253.59074 \\
\hline 24 & A & 155.07273 & A & 1.1312286 & A & 88.099420 & A & 237.14630 \\
\hline 48 & B & 143.38586 & A & 0.7466500 & $\mathrm{~A}$ & 87.831803 & $\mathrm{~A}$ & 238.71111 \\
\hline \multicolumn{9}{|c|}{ Light * Time (h) } \\
\hline Blue * $12 \mathrm{~h}$ & A & 161.70909 & A & 1.0764286 & A B & 87.797328 & A & 245.56296 \\
\hline Blue $* 24 \mathrm{~h}$ & A & 159.28485 & A & 1.5011286 & A B & 87.923796 & A & 247.97037 \\
\hline Blue $^{*} 48 \mathrm{~h}$ & A B & 147.87071 & A & 0.7006571 & A B & 88.375399 & A & 248.43333 \\
\hline $\operatorname{Red} * 12 \mathrm{~h}$ & A B & 154.98182 & A & 0.7319714 & A & 88.693385 & A & 261.61852 \\
\hline Red $* 24 h$ & A B & 150.86061 & A & 0.7613286 & A B & 88.275043 & A & 226.32222 \\
\hline Red * $48 \mathrm{~h}$ & B & 138.90101 & A & 0.7926429 & B & 87.288206 & A & 228.98889 \\
\hline
\end{tabular}

Note: Levels not connected by same letter (A, B) are significantly different. * represents the combination of the two factor levels.

\subsection{Effect of LED Application on Total Colour Change}

The colour indices of the leaves observed before and after treatment have been summarised in Table 4 . The greater value of parameter $L^{*}$ to $L$ (lightness or darkness) implied that treated leaves were lighter in colour after treatment than before treatment. The more positive value of parameter $a^{*}$ than $a$ (green or red) implied an increase in redness of the leaves after treatment; the higher value of parameter $b^{*}$ than $b$ (blue or yellow) implied an increase in yellowness of the leaves. The change in colour increased with an increase in time both in case of application of red and blue light; hence time was found to be the only significant factor.

Table 4. Summary of colour change and ANOVA analysis of the variation of colour change of leaves as affected by the light treatment and time of application.

\begin{tabular}{|c|c|c|c|c|c|c|c|c|}
\hline Light & Time (h) & $L$ & $a$ & $b$ & $L^{\prime}$ & $a^{\prime}$ & $b^{\prime}$ & $\delta E$ \\
\hline Blue & 12 & 39.48 & -14.18 & 21.28 & 40.18 & -14.67 & 21.74 & 0.97 \\
\hline Blue & 24 & 38.67 & -14.74 & 20.23 & 42.11 & -13.90 & 23.26 & 4.66 \\
\hline Blue & 48 & 37.67 & -14.27 & 19.05 & 43.10 & -11.63 & 22.97 & 7.20 \\
\hline Red & 12 & 38.95 & -15.45 & 20.79 & 39.67 & -14.53 & 21.39 & 1.31 \\
\hline Red & 24 & 38.33 & -14.71 & 19.97 & 41.31 & -13.22 & 22.58 & 4.23 \\
\hline Red & 48 & 38.80 & -14.47 & 20.12 & 43.89 & -12.43 & 23.72 & 6.57 \\
\hline \multicolumn{9}{|c|}{$R^{2}=0.923981$, RMSE $=1.129238$} \\
\hline \multicolumn{4}{|c|}{ Term } & \multicolumn{3}{|c|}{ Estimate } & \multicolumn{2}{|c|}{ Prob $>$ F } \\
\hline \multicolumn{4}{|c|}{ Intercept } & \multicolumn{3}{|c|}{4.460739} & \multicolumn{2}{|c|}{0.0107 * } \\
\hline \multicolumn{4}{|c|}{ Light [Blue] } & \multicolumn{3}{|c|}{0.144676} & \multicolumn{2}{|c|}{0.7852} \\
\hline \multicolumn{4}{|c|}{ Time (h) $(12,48)$} & \multicolumn{3}{|c|}{2.720988} & \multicolumn{2}{|c|}{0.0391 * } \\
\hline \multicolumn{4}{|c|}{ Light [Blue] * Time $(\mathrm{h})$} & \multirow{2}{*}{\multicolumn{2}{|c|}{0.219407}} & & \multicolumn{2}{|c|}{0.7305} \\
\hline \multicolumn{4}{|c|}{ Model } & & & & \multicolumn{2}{|c|}{0.1118} \\
\hline
\end{tabular}

Note: * represents significant values. 
In North America, the harvest season of blueberries varies with different cultivars; the fall season is the end of harvesting season after which leaves fall. Blueberry leaves turn red during the fall because of the accumulation of anthocyanins and deterioration of chlorophyll [27], however the degree of redness varies with different cultivars. Some species might have more red leaves than others. The capacity to develop anthocyanins or the rate of deterioration of different colour compounds leading to a change of colour of leaves after harvest depends on the variety as well. Though there was no significant correlation found between the colour change and the monomeric anthocyanin or total phenolics content, it cannot be entirely rejected as strong positive correlation has been observed between redness of blueberry leaves and total monomeric anthocyanin content during our previous studies [24]. As the time of collection of leaves in the current study was near the stage of senescence, there might have been an inherent constraint on the mechanism of development of various phytochemicals and colour components.

Though postharvest UV light application or light application during different stages of growth has been observed leading to accumulation of different types of phenolic compounds [29,30] in different fruits and vegetables, the initial concentration of the target compounds in the biomaterials determines the effect of different light sources applied. In the case of apples, it was observed that the capacity to respond to the application of UV-B wavelength was higher for the apple tissues with lower initial levels of anthocyanins than the apple tissues with higher initial levels [31]. The leaves in the current case were collected during the fall season when the concentration of phenolic compounds are already high and leaves are generally mature, as observed in previous studies also [16,24]. Therefore, it can be deduced that the response of these blueberry leaf tissues in terms of accumulation or increase of the phenolic compounds concentration also depended on the maturity level of the leaves. Hence, the extent of the increase in different responses observed in the current study can be considered as a marked improvement in the quality of leaves, which can be applied and investigated for leaves collected at different periods of the year. Therefore, further research is required to understand the effect of the different wavelengths of light and determine the proper time and stage of collection of the leaves for postharvest application of LED.

\section{Conclusions}

Overall, the application of blue light for a shorter period of time resulted in higher levels of phenolic levels and monomeric anthocyanin content. Though percentage scavenging of DPPH was similar among all samples, application of red light for a shorter period of time led to significantly higher FRAP than in case of untreated leaves. Also, time of application of light was observed to be a significant factor. Though the leaves were harvested in fall season which lead to the inherent high levels of all the responses, application of blue LED for a shorter period of time can be effective for preservation and increase of phenolic components and antioxidant activity of the blueberry leaves. However, further analyses in this direction are required for the development and optimisation of LED application methods to augment highest phenolic accumulation in different biomaterials. Further research is also required to generalize this phenomenon and understand the mechanisms behind the process of accumulation of these compounds and associated increase in antioxidant activity. Similar studies should also be replicated for the leaves collected at different other stages of plant growth.

Author Contributions: W.R. conceptualised the research, conducted experiments and wrote the manuscript. V.O. supervised the project. M.L. supported the project and provided the lab facilities for conducting the experiments.

Funding: The authors thank the Natural Sciences and Engineering Research Council of Canada for the research funding.

Acknowledgments: We are grateful to G.S.V.R. (James McGill Professor, Bioresource Engineering Department, Macdonald Campus, McGill University, Canada) for providing us the facilities to conduct the experiments. We also thank Y.G. (Research Engineer, Bioresource Engineering Department, Macdonald Campus, McGill University, Canada) and R.W. (Research Associate, Bioresource Engineering Department, Macdonald Campus, McGill University, Canada) for their guidance and support during the study. 
Conflicts of Interest: The authors declare no conflicts of interest.

\section{References}

1. Kim, S.M.; Shang, Y.F.; Um, B.H. Preparative separation of chlorogenic acid by centrifugal partition chromatography from highbush blueberry leaves (Vaccinium corymbosum L.). Phytochem. Anal. 2010, 21, 457-462. [CrossRef] [PubMed]

2. Hicks, J.M.; Muhammad, A.; Ferrier, J.; Saleem, A.; Cuerrier, A.; Arnason, J.T.; Colson, K.L. Quantification of chlorogenic acid and hyperoside directly from crude blueberry (Vaccinium angustifolium) leaf extract by NMR spectroscopy analysis: Single-laboratory validation. J. AOAC Int. 2012, 95, 1406-1411. [CrossRef] [PubMed]

3. Routray, W.; Orsat, V. MAE of phenolic compounds from blueberry leaves and comparison with other extraction methods. Ind. Crops Prod. 2014, 58, 36-45. [CrossRef]

4. Harris, C.S.; Burt, A.J.; Saleem, A.; Le, P.M.; Martineau, L.C.; Haddad, P.S.; Bennett, S.A.L.; Arnason, J.T. A single HPLC PAD APCI/MS method for the quantitative comparison of phenolic compounds found in leaf, stem, root and fruit extracts of Vaccinium angustifolium. Phytochem. Anal. 2007, 18, 161-169. [CrossRef] [PubMed]

5. Ehlenfeldt, M.K.; Prior, R.L. Oxygen radical absorbance capacity (ORAC) and phenolic and anthocyanin concentrations in fruit and leaf tissues of highbush blueberry. J. Agric. Food Chem. 2001, 49, 2222-2227. [CrossRef] [PubMed]

6. Grace, M.H.; Ribnicky, D.M.; Kuhn, P.; Poulev, A.; Logendra, S.; Yousef, G.G.; Raskin, I.; Lila, M.A. Hypoglycemic activity of a novel anthocyanin-rich formulation from lowbush blueberry, Vaccinium angustifolium Aiton. Phytomedicine 2009, 16, 406-415. [CrossRef] [PubMed]

7. Chatterjee, A.; Yasmin, T.; Bagchi, D.; Stohs, S.J. Inhibition of Helicobacter pylori in vitro by various berry extracts, with enhanced susceptibility to clarithromycin. Mol. Cell. Biochem. 2004, 265, 19-26. [CrossRef] [PubMed]

8. Cisneros-Zevallos, L. The Use of Controlled Postharvest Abiotic Stresses as a Tool for Enhancing the Nutraceutical Content and Adding-Value of Fresh Fruits and Vegetables. J. Food Sci. 2003, 68, 1560-1565. [CrossRef]

9. Chen, T.H.; Murata, N. Glycinebetaine protects plants against abiotic stress: Mechanisms and biotechnological applications. Plant Cell Environ. 2011, 34, 1-20. [CrossRef] [PubMed]

10. Giri, J. Glycinebetaine and abiotic stress tolerance in plants. Plant Signal. Behav. 2011, 6, 1746-1751. [CrossRef] [PubMed]

11. Eichholz, I.; Huyskens-Keil, S.; Keller, A.; Ulrich, D.; Kroh, L.W.; Rohn, S. UV-B-induced changes of volatile metabolites and phenolic compounds in blueberries (Vaccinium corymbosum L.). Food Chem. 2011, 126, 60-64. [CrossRef]

12. Murugesan, R.; Orsat, V.; Lefsrud, M. Effect of pulsed ultraviolet light on the total phenol content of elderberry (Sambucus nigra) fruit. Food Nutr. Sci. 2012, 3, 774.

13. Heo, J.; Kang, D.; Bang, H.; Hong, S.; Chun, C.; Kang, K. Early growth, pigmentation, protein content, and phenylalanine ammonia-lyase activity of red curled lettuces grown under different lighting conditions. Korean J. Hortic. Sci. Technol. 2012, 30, 6-12. [CrossRef]

14. Lee, N.; Lee, M.-J.; Kim, Y.-K.; Park, J.-C.; Park, H.-K.; Choi, J.-S.; Hyun, J.-N.; Kim, K.-J.; Park, K.-H.; Ko, J.-K.; et al. Effect of light emitting diode radiation on antioxidant activity of barley leaf. J. Korean Soc. Appl. Biol. Chem. 2010, 53, 685-690. [CrossRef]

15. Avercheva, O.; Berkovich, Y.A.; Erokhin, A.; Zhigalova, T.; Pogosyan, S.; Smolyanina, S. Growth and photosynthesis of Chinese cabbage plants grown under light-emitting diode-based light source. Russ. J. Plant Physiol. 2009, 56, 14-21. [CrossRef]

16. Routray, W.; Orsat, V.; Gariepy, Y. Effect of different drying methods on the microwave extraction of phenolic components and antioxidant activity of highbush blueberry leaves. Dry. Technol. 2014, 32, 1888-1904. [CrossRef]

17. Sankat, C.K.; Basanta, A.; Maharaj, V. Light mediated red colour degradation of the pomerac (Syzygium malaccense) in refrigerated storage. Postharvest Biol. Technol. 2000, 18, 253-257. [CrossRef] 
18. Britz, S.; Gaska, I.; Shturm, I.; Bilenko, Y.; Shatalov, M.; Gaska, R. Deep Ultraviolet (DUV) Light-Emitting Diodes (LEDs) to Maintain Freshness and Phytochemical Composition During Postharvest Storage. In Proceedings of the CLEO: 2013 San Jose Convention Center, San Jose, CA, USA, 9-14 June 2013.

19. Samuolienè, G.; Sirtautas, R.; Brazaityte, A.; Duchovskis, P. LED lighting and seasonality effects antioxidant properties of baby leaf lettuce. Food Chem. 2012, 134, 1494-1499. [CrossRef] [PubMed]

20. Larbat, R.; Olsen, K.M.; Slimestad, R.; Løvdal, T.; Bénard, C.; Verheul, M.; Bourgaud, F.; Robin, C.; Lillo, C. Influence of repeated short-term nitrogen limitations on leaf phenolics metabolism in tomato. Phytochemistry 2012, 77, 119-128. [CrossRef] [PubMed]

21. Ma, T.; Zhang, J.; Liang, H.; Liu, Y. Plant anthocyanin synthesis and gene regulation. Agric. Sci. Technol. Hunan 2012, 13, 507-540.

22. Zhou, Y.; Singh, B.R. Effect of light on anthocyanin levels in submerged, harvested cranberry fruit. BioMed Res. Int. 2004, 5, 259-263. [CrossRef] [PubMed]

23. Martz, F.; Jaakola, L.; Julkunen-Tiitto, R.; Stark, S. Phenolic composition and antioxidant capacity of bilberry (Vaccinium myrtillus) leaves in northern Europe following foliar development and along environmental gradients. J. Chem. Ecol. 2010, 36, 1017-1028. [CrossRef] [PubMed]

24. Routray, W.; Orsat, V. Variation of phenolic profile and antioxidant activity of North American highbush blueberry leaves with variation of time of harvest and cultivar. Ind. Crops Prod. 2014, 62, 147-155. [CrossRef]

25. Zhu, L.; Liu, X.; Tan, J.; Wang, B. Influence of Harvest Season on Antioxidant Activity and Constituents of Rabbiteye Blueberry (Vaccinium ashei) Leaves. J. Agric. Food Chem. 2013, 61, 11477-11483. [CrossRef] [PubMed]

26. Feild, T.S.; Lee, D.W.; Holbrook, N.M. Why leaves turn red in autumn. The role of anthocyanins in senescing leaves of red-osier dogwood. Plant Physiol. 2001, 127, 566. [CrossRef] [PubMed]

27. Hoch, W.A.; Zeldin, E.L.; McCown, B.H. Physiological significance of anthocyanins during autumnal leaf senescence. Tree Physiol. 2001, 21, 1-8. [CrossRef] [PubMed]

28. Wu, M.-C.; Hou, C.-Y.; Jiang, C.-M.; Wang, Y.-T.; Wang, C.-Y.; Chen, H.-H.; Chang, H.-M. A novel approach of LED light radiation improves the antioxidant activity of pea seedlings. Food Chem. 2007, 101, 1753-1758. [CrossRef]

29. Percival, G.C.; Baird, L. Influence of Storage upon Light-Induced Chlorogenic Acid Accumulation in Potato Tubers (Solanum tuberosum L.). J. Agric. Food Chem. 2000, 48, 2476-2482. [CrossRef] [PubMed]

30. Dong, Y.-H.; Mitra, D.; Kootstra, A.; Lister, C.; Lancaster, J. Postharvest stimulation of skin color in Royal Gala apple. J. Am. Soc. Hortic. Sci. 1995, 120, 95-100.

31. Reay, P.F.; Lancaster, J.E. Accumulation of anthocyanins and quercetin glycosides in 'Gala' and 'Royal Gala' apple fruit skin with UV-B-Visible irradiation: Modifying effects of fruit maturity, fruit side, and temperature. Sci. Hortic. 2001, 90, 57-68. [CrossRef]

(C) 2018 by the authors. Licensee MDPI, Basel, Switzerland. This article is an open access article distributed under the terms and conditions of the Creative Commons Attribution (CC BY) license (http://creativecommons.org/licenses/by/4.0/). 